\title{
INDUÇÃO AO ESTRO EM VACAS LEITEIRAS DA RAÇA HOLANDESA EM ANESTRO PUERPERAL E PÓS-PUERPERAL, MEDIANTE ADMINISTRAÇÃO DE FÓSFORO ORGÂNICO ASSOCIADO À VITAMINA B12
}

\author{
E strus induction in holstein cows breed during puerperal and post \\ puerperal period, by administration of organic phosphorus and vitamin B12
}

\author{
Alceu Grebogi ${ }^{a}$, Felipe Pohl de Souza ${ }^{\text {b }}$ Luiz Ernandes Kozickic \\ José Carlos dos Santos Breda ${ }^{\mathrm{d}}$, Alisson Bruno de Moraes Giacomeli ${ }^{\mathrm{e}}$
}

\footnotetext{
a Zootecnista (PUCPR), Fazenda Rio G rande,PR - Brasil, e-mail:alceugrebogi@ gmail.com

${ }^{\mathrm{b}}$ Médico Veterinário MSc. Professor (PUCPR), Curitiba, PR - Brasil, e-mail: f.pohl@ globo.com

c Médico Veterinário, PhD . Professor (PUCPR), Curitiba, PR - Brasil, e-mail: kozicki@ ufpr.br

${ }^{d}$ G raduando em Medicina V eterinária (PUCPR), São José dos Pinhais, PR - Brasil, e-mail: josecarlosbreda@ yahoo.com.br

${ }^{\text {e }}$ G raduando em Medicina V eterinária (PUCPR), São José dos Pinhais, PR - Brasil, e-mail: alissongiacomeli@ yahoo.com.br
}

\begin{abstract}
Resumo
O objetivo do presente trabalho foi de induzir o retorno à atividade cíclica de vacas leiteiras em anestro puerperal e pós-puerperal mediante a administração de fósforo orgânico associado à vitamina B12. Foram utilizados 50 animais de elevada produção leiteira da raça holandesa procedentes da Fazenda Experimental G ralha Azul - PUCPR, localizada no município de Fazenda Rio G rande- PR. O s animais foram divididos em três grupos (G1, G 2 e G 3), sendo o grupo $\mathrm{G} 1$ constituído por 22 animais que se encontravam em anestro após o parto de 30-60 dias, o G 2 por 23 animais que se encontravam em anestro de 61-90 dias e G3 constituído por 5 animais que se encontravam em anestro de 91-150 dias pós-parto. 0 critério para 0 início do tratamento com fósforo orgânico associado à vitamina B12 foi a identificação da condição anéstrica via palpação retal, onde o parâmetro utilizado para a identificação do anestro era a não existência de estruturas nos ovários, ou seja, ausência de folículo dominante ou de folículos subordinados grandes ou de corpo lúteo. 0 tratamento adotado seguiu o seguinte protocolo: $4000 \mathrm{mg}$ de fósforo (P) orgânico a 10\% aplicados via intramuscular (IM) no primeiro dia após a identificação do anestro, $3000 \mathrm{mg}$ (IM) após três dias e mais $3000 \mathrm{mg}$ (IM) três dias após, como a terceira aplicação. Com os resultados obtidos, verificou-se que em torno de duas semanas após o tratamento houve o retorno dos animais ao cio ( $p>0,05)$ em respectivamente 59, 56 e 80\% dos animais dentro de 11,4; 14,8 e 13,0 dias para o G 1, G 2 e $\mathrm{G}$ 3. Concluiu-se que a administração intramuscular do fósforo orgânico, associado à vitamina B12, não demonstrou significativa eficiência reprodutiva entre os grupos pesquisados, muito embora tenha havido resposta nos três grupos, dentro das duas semanas após sua administração.
\end{abstract}

Palavras-chave: Fósforo orgânico; A nestro; Puerpério; Vacas leiteiras. 


\begin{abstract}
The objective of this research work was to induce a return to cyclical activity of dairy cows in anoestrus through the application of organic phosphorus associated with vitamin B12 (Catosal (B). We used 50 animals with high production from the Fazenda Experimental Gralha Azul PUCPR, Fazenda Rio Grande PR. The animals were divided into three groups (G1, G2, G3), and G1 the group consisting of 22 animals that were in anoestrus 30-60 days after delivery, the G2 for 23 animals that were in anoestrus 61-90 days after delivery and G3 consists of 5 animals that were in anoestrus 91-150 days after delivery. The criteria for the start of treatment with organic phosphorus associated with vitamin B12 was the identification of anoestrus after the period puerperal physiological by rectal palpation. The parameters used for identification of anoestrus were the lack of ovarian follicle or corpus luteum. The treatment was assigned: 4000 mg applied through IM (intramuscular) on the first day after the identification of the animal in anoestrus; $3000 \mathrm{mg}$ (IM) after three days as a second application and more $3000 \mathrm{mg}$ three days after the second application totaling three applications in a concentration of $10 \%$ of the product. The results in percentage of animals with heat were respectively, 59\% and $10.1 \pm 7.01$ for G1; $56 \%$ and $13.6 \pm 6.34$ for $G 2$ and $80 \%$ and $13 \pm 9.76$ for G3. In conclusion: the treatment of anoestrus using organic phosphorus associated with vitamin B12 showed no statistical difference among groups, although the animals answered estrus within two weeks.
\end{abstract}

Keywords: Organic phosphorus; Anoestrus; Puerperium; Dairy cows.

\title{
INTRODUÇÃO
}

Um baixo desempenho reprodutivo determina menor produção de leite e de bezerros, incremento nas despesas de manutenção com vacas secas, maiores taxas de descarte e maior número de doses e sêmen por concepção. A eficiência reprodutiva de um rebanho é um dos componentes mais importantes na performance econômica de uma propriedade de produção de leite (LEITE et al., 2001). A eficiência reprodutiva dos rebanhos bovinos leiteiros no Brasil é baixa, com intervalo de partos próximo a 20 meses (FERREIRA, 1991). Ferreira et al. (1992) encontraram apenas 16,2\% de concepção até 90 dias pós-parto em 1.674 gestações de 50 rebanhos leiteiros da Zona da Mata de Minas Gerais, com a grande maioria dos animais não-gestantes, apresentando baixa condição corporal (magros), característica de subnutrição e ovários inativos. 0 anestro pode persistir por vários meses atrasando 0 cio e a concepção, e é a maior causa da baixa taxa de gestação em bovinos resultante na maioria dos casos da diminuída taxa de ingestão de alimentos e da mobilização das reservas corporais, entrando o animal em balanço energético negativo e, consequentemente, interrompendo a atividade ovariana. 0 peso ao primeiro parto é considerado o mais importante fator, influenciando a prenhez na reconcepção de vacas primíparas. Estima-se que vacas perdem de 25 a 30\% de seu peso adulto quando acometidas por (atrofia de órgãos reprodutivos). Fêmeas mais leves e com condição corporal moderada apresentam, entretanto, menor porcentagem de perda de peso (6-10\%) nas primeiras semanas do pós-parto é capaz de levar ao anestro (FERREIRA, 1993). A esterilidade ou infertilidade de origem nutricional caracteriza-se por ausência do ciclo estral e do estro, definido como anestro, e sob condição de subnutrição por curto período ou menos severa, por falha na fertilização ou morte embrionária precoce (ROBERTS, 1971). A intensificação dos sistemas de produção de leite indica que as vacas devem ser cobertas o mais cedo possível após o parto. No entanto, os melhores índices de fertilidade são obtidos com serviços a partir dos 60 dias pós-parto. Algumas enfermidades puerperais e metabólicas (STEVENSO N; CALL, 1988), bem como deficiente detecção de cio (E SSLEMO NT, 1993) podem ser responsáveis pela subfertilidade, prolongando o intervalo parto-concepção. No caso de fêmeas em reprodução, as respostas podem ser diferentes, em razão da maior necessidade de minerais em certas fases da gestação e da lactação, às vezes 
Indução ao estro em vacas leiteiras da raça holandesa em anestro puerperal e pós-puerperal, mediante administração de fósforo orgânico associado à vitamina B12

coincidindo com o período de seca. Bovinos podem lançar mão das reservas ósseas de cálcio e de fósforo para manter as concentrações desses elementos adequadas para suportar processos metabólicos essenciais. Entretanto, se essa condição for mantida, a deficiência clínica será estabelecida.

A deficiência de fósforo $(\mathrm{P})$ é extremamente prejudicial na criação extensiva de bovinos e amplamente verificada na maioria dos países tropicais (UNDERWOOD , 1996). D eficiências desse elemento têm sido associadas com reduções no consumo e crescimento, apetite reduzido, redução na produção de leite e distúrbios reprodutivos (PRESTON et al., 1977; BUTTERWORTH, 1985; UNDERWOOD, 1996). Resultados da análise de 500 amostras de gramíneas oriundas da América

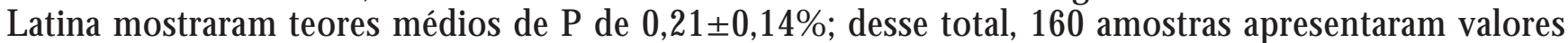
inferiores a 0,15\% (McD OWELL et al., 1974).

Inúmeros trabalhos foram realizados nos trópicos e subtrópicos, com o objetivo de investigar o efeito do $\mathrm{P}$ suplementar no desempenho de bovinos em pastejo. D evido à enorme variação ambiental nesse tipo de experimento, respostas animais aos tratamentos têm sido bastante variáveis, sendo algumas vezes positivas (MORAN, 1973; GRANT, 1976; McD O WELL et al., 1982), outras sem efeito (RHODES, 1956; LAMPKING, 1961; WINKS et al., 1976; WINTER; EDYE; WILLIAMS, 1977; VALLE; SO UZA; NUNE S, 1982) ou de resposta estacional (VAN SCHALKWYK; LO MBARD, 1969; WINKS; LAMBERTH; O'ROURKE, 1977). Um aspecto a ser considerado diante dessa diversidade de respostas ao $\mathrm{P}$ suplementar seria a existência de outros nutrientes prioritariamente limitantes ao desempenho normal do animal, resultado dos diversos ecossistemas pastoris onde esses estudos foram realizados. Por exemplo, numa situação em que o teor de $\mathrm{N}$ amoniacal no líquido ruminal for inferior a $150 \mathrm{mg} / \mathrm{L}$ (PRESTON; LENG, 1987), a probabilidade de resposta animal a uma suplementação com $\mathrm{P}$ será muito pequena. Essa é uma situação que normalmente ocorre em áreas tropicais, principalmente durante o período de seca, quando níveis proteicos nas pastagens ficam abaixo dos 6,2\% na matéria seca (MINSO N , 1990). Na maioria dos casos em que P está deficiente, a proteína também está, e se o primeiro é suplementado sem a devida correção do segundo, as chances de obter respostas ao P serão bastante reduzidas (PLAYNE; SIEBERT; EDYE, 1975). 0 presente trabalho tem como objetivo induzir o retorno à ciclicidade ovariana mediante administração de fósforo orgânico associado à vitamina B12 em vacas leiteiras que se encontravam em anestro pós-parto de 30 a 150 dias.

\section{MATERIAL E MÉTODOS}

Foram utilizados 50 animais da raça holandesa, procedentes da Fazenda Experimental G ralha Azul - PUCPR, localizada no município de Fazenda Rio Grande, PR, alimentados com dieta composta por silagem de milho (28\% MS), resíduo de cevada (21\% MS), feno de tifton (87,6\% MS), ração agrária VL-19 (88.8 \% MS), farelo de soja (87.5\% MS), milho moído (88\% MS), gordura protegida (95\% MS), bicarbonato de sódio, 99\%), sal mineral (99\% MS) e calcário (99\% MS), em que os níveis de consumo em kg MS/ vaca/ dia estimados foram: 10,62; 2,10; 0,64; 7,99; 2,63; 0,88; 0,29; 0,20; 0,15; $0,10 \mathrm{~kg}$ respectivamente de acordo com os produtos citados. A produção leiteira em 305 dias de lactação atingiu 11 mil litros.

O critério utilizado para o início do procedimento de administração (IM) do fósforo orgânico era identificar 0 anestro pós-parto das vacas mediante palpação retal dos ovários. Estabeleceu-se como critérios para 0 anestro nestes animais: a ausência de cio desde 0 parto; a ausência de folículo ovariano dominante ou ausência de corpo lúteo em qualquer dos ovários. A partir daí era adotado um protocolo de $4000 \mathrm{mg}$ de fósforo orgânico associado à vitamina B12 na primeira aplicação, $3000 \mathrm{mg}$ três dias depois, como segunda aplicação e $3000 \mathrm{mg}$ três dias depois da segunda aplicação totalizando em 3 aplicações na concentração de $10 \%$ do produto, tendo-se que um aumento do incremento calórico causado pelo estímulo do metabolismo que o P (fósforo) promove no organismo, podendo influenciar no balanço energético negativo em que o animal se encontra no pós-parto. Subsequentemente, os animais foram divididos basicamente em três grupos, sendo: Grupo 1 (G1) com 22 animais que se encontravam em anestro no período de 30 a 60 dias pós-parto, Grupo 2 (G2) com 23 animais que se 
encontravam em anestro no período de 61 a 90 dias e G rupo 3 (G 3) com 5 animais que se encontravam em anestro no período de 91 a 150 dias pós-parto. A pós a administração da droga, os animais tratados eram submetidos à observação diária do cio durante os períodos da manhã e tarde e inseminados artificialmente (IA). Considerou-se como resposta ao tratamento, os animais que manifestaram o estro até 23 dias após a aplicação.

Como tratamentos estatísticos foram empregados o teste " $\mathrm{t}$ " de STUDENT e o teste do QUI-QUAD RAD 0 para avaliar a significância entre os grupos.

\section{RESULTADOS E DISCUSSÃO}

Os resultados podem ser observados na Tabela 1.

TABELA 1 - Resultados obtidos após administração de fósforo orgânico associado à vitamina B12 (IM) em diferentes períodos do pós-parto de vacas leiteiras em anestro, Fazenda Rio Grande, PR $(n=50)$

Table 1 - Results obtained after administration of organic phosphorus (IM) associated with vitamin B12 in different periods of post-partum of dairy cows in anoestrus, Fazenda Rio G rande, PR $(\mathrm{n}=50)$

\begin{tabular}{lllll}
\hline Grupos & $\begin{array}{l}\text { Grupos segundo o } \\
\text { intervalo de dias } \\
\text { em anestro p.p (dias) }\end{array}$ & $\begin{array}{l}\text { Tratamento p.p } \\
\text { (dias) } \\
(\text { encontrados) } \\
(\mathrm{x} \pm \mathrm{s})\end{array}$ & $\begin{array}{l}\text { Estro após o } \\
\text { tratamento (dias) } \\
(\mathrm{x} \pm \mathrm{s})\end{array}$ & $\begin{array}{l}\text { Percentual de } \\
\text { resposta de cio } \\
\text { pós-tratamento } \\
(\%)\end{array}$ \\
\hline G 1 (n=22) & $30-60$ & $49,8 \pm 9,2$ & $11,4 \pm 7,4 \mathrm{a}$ & $59,0 \mathrm{~A}$ \\
G 2 (n=23) & $61-90$ & $71,7 \pm 8,4$ & $14,8 \pm 6,5 \mathrm{~b}$ & $65,2 \mathrm{~B}$ \\
G 3 (n=5) & $91-150$ & $112,0 \pm 23,5$ & $13,0 \pm 9,7 \mathrm{C}$ & $80,0 \mathrm{C}$ \\
\hline$(\mathrm{n}=50)$ & & & & \\
\hline
\end{tabular}

A análise estatística não demonstrou significância, em quaisquer das variáveis confrontadas.

Os resultados expressos na Tabela 1 relativamente ao percentual de resposta dos animais ao manifestarem o cio (59,0; 65,2 e 80,0\% nos grupos G1, G 2 e G 3 respectivamente), frente ao tratamento administrado, demonstraram que este não apresentou significância entre os grupos, apesar de alguns pesquisadores afirmarem que o P é tido como mineral da reprodução, acarretando maior taxa de fertilidade (CARVALHO et al., 2003). Como se observa, os animais do G3 foram os que melhor responderam ao tratamento $(p>0,05)$, provavelmente porque essas vacas já haviam atingido o pico da lactação e se encontravam em processo de estabilização não só sobre a produção de leite como também em melhor escore da condição corporal, fundamentando-se nos relatos de Frandson, Leewilkwe e Sails (2005).

Ao se comparar os grupos, quanto ao número de dias obtido como resposta de estro frente ao tratamento aplicado, igualmente não se verificou significância. Contudo sugere-se que a administração do P inorgânico, poderia abreviar o tempo em que esses animais permaneceriam em anestro, acarretando a vinda ao estro em curto espaço de tempo como se observa (11,4 dias; 14,9, e aos 13,0 dias nos grupos G 1, G 2 e G 3 respectivamente na Tabela 1. Em pesquisa realizada por D oyle, Huston e Thompson (1990), foram constatadas significativas melhorias no tecido endometrial de bovinos, ao se administrar P aos animais, implicando em benefícios à ciclicidade reprodutiva. Melhorias no desempenho reprodutivo de vacas leiteiras foram citadas por Lamothe, Busquet e Guay (1976), os quais relatam a presença de significativos níveis de $\mathrm{P}$ presentes nos fluidos uterinos durante 0 estro nos animais. Os autores supracitados afirmam a existência de efeitos indiretos causados pelo elemento $\mathrm{P}$ no organismo, associados a uma modificação no ambiente uterino, favorecendo o desempenho reprodutivo dos bovinos. 
Indução ao estro em vacas leiteiras da raça holandesa em anestro puerperal e pós-puerperal, mediante administração de fósforo orgânico associado à vitamina B12

\section{CONCLUSÃO}

Com base nos dados verificados no presente trabalho, concluiu-se que a administração intramuscular (IM) do fósforo orgânico associado à vitamina B12, não demonstrou significativa eficiência reprodutiva entre os grupos pesquisados, muito embora tenha havido resposta dentro de duas semanas nos animais pesquisados.

\section{REFERÊNCIAS}

BUTTERWORTH, M. H. Phosphorus deficiencies and their correction. In: . Beef cattle nutrition and tropical pastures. London: Logman, 1985. p. 40-75.

CARVALHO, F. A. N.; BARBOSA, F. A.; McDOWELL, L. R. Nutrição de bovinos a pasto. Belo Horizonte: Papel Form, 2003.

DOYLE. J. C.; HUSTON. J. E.; THOMPSON, P. V. Influence of mineral supplementation on bovine serum, liver and endometrium at Day 1 and Day 12 of the estrus cycle. Theriogenology, v. 34, n. 1, p. 21-31, 1990.

ESSLEMONT, R. J. Relationship between herd calving to conception interval and culling rate for failure to conceive. Veterinary Record, v. 133, p. 163-164, 1993.

FERREIRA, A. de M. Manejo reprodutivo e sua importância na eficiência da atividade leiteira. Coronel Pacheco: Embrapa-CNPGL, 1991. (Embrapa-CNPG L. D ocumentos, 46).

FERREIRA, A. de M. et al. D iagnóstico da situação produtiva e reprodutiva em rebanhos leiteiros da Zona da Mata-MG. Pesquisa Agropecuária Brasileira, v. 27, n. 1, p. 91-104, 1992.

FERREIRA, A. M. Nutrição e atividade ovariana em bovinos: uma revisão. Pesquisa Agropecuária Brasileira, v. 28, n. 9, p. 1077-1093, 1993.

FRANDSON, R. D.; LEEWILKW, W.; SAILS, A. D. Anatomia e fisiologia dos animais de fazenda. 6. ed. Rio de Janeiro: Guanabara Koogan, 2005. p. 408-409.

GRANT, J. L. Response of steers to phosphorus supplementation and zeranol. Rhodesia Annual Report 1975/ 76, p. 68-70, 1976.

LAMOTHE, P.; BUSQUET, D.; GUAY, P. Influence of exogenous phosphorus on uterine fluids composition. Theriogenology, v. 6, n. 4, p. 353-365, 1976.

LAMPKING, G. H. Studies on the production of beef from Zebu cattle in East Africa. III. The value of feeding a phosphatic supplement. Journal of Agricultural Science, v. 57, n. 1, p. 39-47, 1961.

LEITE, T. E.; MORAES, J. C. F.; PIMENTEL, C. A. Eficiência produtiva e reprodutiva em vacas leiteiras, Ciência Rural, v. 31, n. 3, p. 1-15, 2001.

McD OWELL, L. R. et al. Latin American table of feed composition. Gainesville: University of Florida, 1974.

McD OWELL, L. R. et al. Mineral supplementation of beef cattle in the Bolivian tropics. Journal of Animal Science, v. 55, n. 4, p. 964-970, 1982.

MINSON, D. J. Forage in ruminant nutrition. New York: Academic, 1990.

MORAN, J. B. Effect of meat-and-bone meal supplements on growth of weaner cattle on dry season improved pasture at Adelaide River, N.T. Australian Journal of Experimental Agriculture and Animal Husbandry, v. 13, n. 61, p. 134-141, 1973. 
PLAYNE, M. J.; SIEBERT, B. D.; EDYE, L. A. The use of non-protein nutrients with cattle grazing improved pastures in the Australian dry tropics. In: WORLD CONFERENCE ON ANIMAL PROD UCTION, 3., 1973, Melbourne. Proceedings... Adelaide: Sydney University Press, 1975. p. 574-579.

PRESTON, L. R. et al. Phosphorus in ruminant nutrition. Iowa: National Feed Ingredients Association, 1977.

PRESTON, T. R.; LENG, R. A. Matching ruminant production systems with available resources in the tropics and Sub-Tropics. Armidale: Penambul Books, 1987.

RHODES, F. B. The effect of feeding mineral protein and carbohydrate supplements to growing beef cattle in Mashonaland. Rhodesia Agricultural Journal, v. 53, p. 969-982, 1956.

ROBERTS, S. J. Veterinary obstetrics and genital diseases. Michigan: Ann Arbor Edward Brothers, 1971.

STEVENSO N, J. S.; CALL, E. P. Reproductive disorders in the periparturient dairy cow. Journal of Dairy Science, v. 71, n. 9, p. 2572-2583, 1988.

UNDERWOOD, E. J. The mineral nutrition of livestock. Aberdeen: FAO/ CAB, 1996.

VALLE, E. R. do; SOUZA, J. C.; NUNES, S. G. Suplementação mineral de fêmeas Neloradas criadas em Campo nativo. In: REUNIÃO ANUAL DA SOCIEDADE BRASILEIRA DE ZO OTECNIA, 19., 1982. Piracicaba. Anais... Piracicaba: ESALQ, 1982. p. 217-218.

VAN SCHALKWYK, A.; LOMBARD, P. E. The influence of phosphorus supplementation on body function and growth of young steers. Agroanimalia, v. 1, p. 45-52, 1969.

WINKS, L. et al. Effect of nitrogen, phosphorus and molasses supplements on the performance of weaner cattle during the dry season in North Q ueensland. Journal of the Australian Institute of Agricultural Science, v. 42, p. 246-251, 1976.

WINK S, L.; LAMBERTH, F. C.; O'ROURKE, P. K. The effect of phosphorus supplement on the performance of steers grazing Townsville stylo-based pasture in north Queensland. Australian Journal of Experimental Agriculture and Animal Husbandry, v. 17, n. 86, p. 357-366, 1977.

WINTER, W. H.; EDYE, L. A.; WILLIAMS, W. T. Effects of fertilizer and stocking rate on pasture and beef production from sown pastures in northern Cape York Peninsula. 2. Beef production and its relation to blood, fecal and pasture measurements. Australian Journal of Experimental Agriculture and Animal Husbandry, v. 17, n. 84, p. 66-74, 1977.

Recebido: 06/ 04/ 2008 R eceived: 04/ 06/ 2008

Aprovado: 14/ 04/ 2008

A pproved: 04/ 14/ 2008 